\title{
Integration versus decomposition in the retention of complex ideas
}

\author{
JOHN T. E. RICHARDSON \\ Brunel University, Uxbridge, Middlesex, England
}

\begin{abstract}
Four accounts of the processes underlying the retention of connected sentences expressing complex ideas were critically evaluated and experimentally compared. The constructive theory and the imagery theory emphasized the integration of the information expressed by different stimulus items; the tally theory and the fragmentation theory emphasized the decomposition of the information contained within individual stimulus items. In Experiment 1, concrete ideas did not show better integration than abstract ideas, and imagery mnemonic instructions failed to enhance the integration of concrete ideas; these findings were inconsistent with the imagery theory. Moreover, the detailed pattern of performance was inconsistent with specific predictions of the tally theory. In Experiments 2 and 3, a componential analysis was found to provide an accurate representation of performance in cued recall. However, patterns of recall were found that could not have resulted from a fragmentation process, but only from the integration of information from different stimulus items. Once again, concrete ideas did not show significantly better integration than abstract ideas. These findings support a constructive approach, according to which the synthesis of information into holistic representations involves abstract semantic processes that do not depend upon the use of mental imagery.
\end{abstract}

When normal adult subjects try to remember examples of connected narrative, it is intuitively reasonable to suppose that they integrate the information contained within the individual phrases or sentences into higher order semantic representations. However, some psychologists have proposed instead that the encoding of connected narrative involves the decomposition of the stimulus material into simple propositional elements. The purpose of the present study was to employ a recognition paradigm and a cued-recall paradigm in order to test four different theories concerning the integration or decomposition of structured linguistic material.

\section{THE CONSTRUCTIVE THEORY}

The recognition paradigm was devised by Bransford and Franks (1971), who asked their subjects to listen to a set of sentences that together defined a complex idea. For example, the complex idea "The ants in the kitchen ate the sweet jelly which was on the table" consisted of the four elements "The ants were in the kitchen," "The jelly was on the table," "The jelly was sweet," and "The ants ate the jelly." The acquisition sentences in their original

The author is grateful for the comments and advice of Allan Paivio, Stephen Monsell, Martin Le Voi, Vernon Gregg, and an anonymous reviewer. He is also grateful to Tamar Mindel for scoring the responses obtained in Experiments 2 and 3. Experiment 1 was reported at the London Meeting of the Experimental Psychology Society in January 1980. Experiments 2 and 3 were reported at the Manchester Meeting of the Experimental Psychology Society in March 1983. Requests for reprints should be addressed to John T. E. Richardson, Department of Psychology, Brunel University, Uxbridge, Middlesex UB8 3PH, England. experiment contained one, two, or three of the elements from any one of four different complex ideas. After the presentation of each acquisition sentence, the subjects carried out a brief color-naming task and then answered a simple elliptical question about that sentence. When all of the acquisition sentences had been presented, the subjects received a recognition test with sentences containing one, two, three, or four elements of each idea. Their confidence that a sentence had been presented for learning was found to vary directly with the number of elements of a particular complex idea that it contained. Moreover, a second experiment demonstrated that such confidence ratings were largely independent of whether or not a sentence had actually been presented during the acquisition phase. These original findings were subsequently replicated both by Bransford and Franks (1972) and by other investigators (Cofer, 1973; Griggs, 1974; Katz, 1973; Katz, Atkeson, \& Lee, 1974; Singer, 1973).

Bransford and Franks (1971) came to two major conclusions. First, the subjects' failure to discriminate between "old" and "new" test sentences was taken to imply that they had lost any information about the specific acquisition sentences that had been presented. Instead, Bransford and Franks proposed that their subjects had abstracted or integrated the propositional content of the sets of individual acquisition sentences to construct holistic semantic ideas. Performance in subsequent retention tests would therefore be based upon information about these integrated representations, rather than upon memories for those particular sentences that had occurred during the acquisition phase of the task (Bransford \& Franks, 1972). Bransford, Barclay, and Franks (1972) described this as a "constructive" approach to sentence memory. 
Second, the correlation between the confidence ratings that were assigned to a test sentence and the number of elements that it contained suggested that the subjects' recognition judgments had been based upon the degree of overlap between a test sentence and the semantic relationships that were characteristic of a complete idea. This decision rule solved the subjects' problem of distributing their responses among a large number of confidence ratings in the absence of any information about the specific acquisition sentences. Bransford and Franks (1971) noted that a different outcome might be obtained if subjects were provided with additional cues to employ in selecting their responses. For instance, if each acquisition sentence contained only one or two elements of a complex idea, test sentences containing three or four elements might be rejected as being inconsistent with the general style of the acquisition material. This was subsequently confirmed in several different investigations (Bransford \& Franks, 1972; Flagg, 1976; Katz et al., 1974; Pezdek, 1978).

Nevertheless, in the absence of any information about the specific acquisition sentences, and in the absence of any concomitant information about the general style of the acquisition material, James, Hillinger, and Murphy (1977) showed that the overall relationship between the subjects' responses and the number of elements in a test sentence was purely the result of variations in response bias. Such biases can apparently be overridden by appropriate experimental instructions; thus, the confidencerating function is essentially horizontal when subjects are required to judge whether test sentences have the same meaning as acquisition sentences (Katz, 1973; Moeser, 1975). James and Hillinger (1977) discussed a variety of other procedural variables that also tend to disrupt the original monotonic relationship between the subjects' confidence ratings and the number of elements in a test sentence. However, it follows that the presence or absence of this overall relationship is quite uninformative of the nature of the underlying representation of semantic content. A fortiori, it is not in itself an indicator of the occurrence of abstraction or integration.

\section{THE IMAGERY THEORY}

A rather different account of sentence memory was given by Paivio (1971a, 1971b, p. 53; see also Begg \& Paivio, 1969), who proposed that concrete sentences were stored in memory as mental images, but that abstract sentences were stored in a relatively superficial verbal form, as "implicit auditory-motor representations." In Bransford and Franks's (1971) original study, the sentences to be remembered described concrete events and situations and readily evoked mental imagery. Indeed, Neisser (1972) suggested that the "holistic semantic ideas" posited by Bransford and Franks might actually consist of composite mental images. In fact, Paivio's imagery theory implies that the abstraction and integration of semantic information should be difficult or impossible in the case of abstract material. According to the constructive theory of Bransford and Franks (1971), however, the synthesis of holistic representations involves the operation of semantic processes that should not be affected by the concreteness of the stimulus material. In order to test these predictions, Franks and Bransford (1972) used abstract ideas in repeating their original experiments and obtained a similar pattern of results. This indicated that the synthesis of information into holistic representations had occurred in the case of both concrete and abstract material and did not depend upon the concretization of that information in the form of mental imagery (see Bransford et al., 1972).

Moeser (1975) pointed out that the question of whether stimulus concreteness affects the process of semantic integration can really be resolved only by comparing concrete and abstract ideas within the same experiment. Studies that satisfied this requirement were carried out by James et al. (1977) and by Richardson (1983), and they found no sign of any difference between concrete and abstract material in terms of the degree of semantic integration (see also Moeser, 1975). However, both these studies and that of Franks and Bransford (1972) can be regarded as subject to ceiling effects insofar as the process of semantic integration is concerned. The occurrence of abstraction and integration was inferred from the subjects' failure to discriminate between old and new test sentences. Conversely, the retention of information about the specific acquisition sentences (whether in a relatively superficial, verbatim form or at some "deeper"' level) would have been inferred from a significant difference between old and new test sentences in terms of the subjects' recognition judgments. Since all three of these investigations showed virtually complete integration, even with abstract material, none of them constitutes a rigorous test of the hypothesis that concrete ideas are integrated more readily than abstract ideas. ${ }^{1}$

Bransford and Franks (1972) suggested that information concerning the specific acquisition sentences should be more readily retained in the case of those with fewer elements. Indeed, a significant difference between old and new test sentences containing only one element of a complex idea does seem to be a reliable outcome of experiments with both concrete and abstract material (Bransford \& Franks, 1971; Franks \& Bransford, 1972; Richardson, 1983; see also James \& Hillinger, 1977, and James et al., 1977). One reason for this might be restrictions on the capacity of immediate memory. When asked to remember passages of connected prose, subjects are apparently able to demonstrate a retention of the precise wording only for the last sentence presented, and possibly only for the last clause presented (Jarvella, 1970; Jarvella \& Herman, 1972; Sachs, 1967). It follows that the verbatim rehearsal of acquisition sentences containing more than one clause is likely to be difficult or impossible, and therefore the retention of specific information would be demonstrated only in the case of the shorter, less complex acquisition sentences. Another possibility, suggested by James and Hillinger (1977), is that acquisi- 
tion sentences that contain only one element are inherently more discriminable from other sentences than those that contain two or more elements. James et al. (1977), however, suggested that the apparent advantage of simpler sentences in the retention of specific information was purely the result of variations in response bias. When a bias-free measure of recognition accuracy $\left(d^{\prime}\right)$ was computed from the proportion of positive responses made to old and new test sentences, there was no clear effect of the number of elements in a test sentence. Nevertheless, their experiment was also subject to a ceiling effect with respect to the hypothetical processes of semantic integration, since the maximum value of $d^{\prime}$ obtained under any condition was only .62 .

It is therefore pertinent to consider experimental manipulations that might attenuate the integration of semantic information and thus permit a more valid comparison of performance with concrete and abstract material. Such manipulations would apparently include the employment of intentional learning, as opposed to incidental learning (see James et al., 1977), and, trivially, reducing the amount of information presented during the acquisition phase concerning each complex idea to the bare minimum consistent with the possibility of forming a holistic semantic representation. These procedures were adopted in the case of the first experiment reported in this paper. As in previous research, the retention of information about the specific acquisition material was measured by comparing the recognition judgments made to old and new test sentences expressing the same complex ideas. In addition, the retention of the ideas themselves as general themes underlying the acquisition material was measured by comparing the recognition judgments made to new sentences expressing those ideas with judgments made to new sentences expressing entirely different ideas.

If, on the one hand, mental imagery is involved in the integrative storage of verbal material, then instructing subjects to use mental imagery as a mnemonic strategy should affect the pattern of recognition performance in Bransford and Franks's (1971) paradigm. Experiment 1 therefore manipulated the concreteness of the stimulus material and the mnemonic instructions given to the subjects in an orthogonal manner. According to the imagery theory of Paivio (1971a, 1971b), abstract sentences are stored in the form of implicit auditory-motor representations, but the creation of interactive mental images is the only basis of integrative storage in long-term memory. On the basis of the results obtained in the retention of individual words (Richardson, 1980, p. 95), the theory would predict that the retention and integration of concrete ideas should be enhanced by imagery mnemonic instructions. However, no such facilitation should be found in the case of abstract material. Indeed, interactive imagery instructions might well disrupt the retention of abstract ideas because of the difficulty of finding appropriate mental images (see Paivio, 1971b, p. 359). The critical determinant of the degree of semantic integration of different ideas should be the relative ease or difficulty with which the relevant sentences evoke mental imagery, as an index of the availability of the hypothesized imaginal code (Paivio, 1972).

On the other hand, according to the constructive theory of Bransford and Franks (1971), the integration of complex ideas is mediated by abstract semantic processes rather than by interactive mental imagery. It follows that neither stimulus concreteness nor imagery mnemonic instructions should facilitate these integrative processes. Indeed, the use of imagery mnemonic instructions should simply encourage the subjects to engage in an additional cognitive task that was functionally irrelevant to their learning. Because of the reduced processing capacity or reduced processing time available for the primary task, such instructions might attenuate the level of semantic integration achieved, or they might disrupt the subjects' retention of the specific acquisition sentences. Once again, this disruption should be more pronounced in the case of abstract ideas, because of the difficulty of finding appropriate mental images. However, the critical determinant of the degree of integration of different ideas (or, equivalently, of the degree of retention of the specific acquisition sentences) should be the latency with which the relevant sentences evoke mental imagery, as an index of the time spent on the additional secondary task of creating mental images (Paivio, 1972).

\section{THE TALLY THEORY}

The constructive theory and the imagery theory disagree over the hypothesized mechanism of semantic integration when subjects are required to learn sets of related sentences. Nevertheless, it has been seriously questioned whether Bransford and Franks's (1971) paradigm demonstrates any process of abstraction and integration at all. Reitman and Bower (1973) proposed, instead, that a complex stimulus might be represented in memory by all of its possible components, and that each component would be tagged following its occurrence in the acquisition phase of an experiment. Thus, if a particular acquisition item containing three elements is symbolized by the expression $\mathrm{ABC}$, the individual elements $(\mathrm{A}, \mathrm{B}$, and $\mathrm{C})$, the three possible digrams ( $\mathrm{AB}, \mathrm{AC}$, and $\mathrm{BC})$, and the trigram itself $(\mathrm{ABC})$ would all be tagged. In a subsequent recognition test, each element of a test item would be inspected, and the item would be rejected as "new" if the number of tags on any one element failed to reach a certain threshold. Otherwise, and if the particular test item contained two or more elements, an accumulating tally would be computed on the basis of each possible digram of those elements. If the number of tags on a specific digram exceeded a certain threshold, then a tally would be added to a counter for that test item; if not, then a tally would be subtracted. Similarly, if the test item contained three or more elements, each possible trigram would be inspected. The confidence rating that would be produced in response to each test item was assumed to be a linear transformation of the accumulated tally for that item.

Reitman and Bower (1973) assumed that every element 
in a test item would be recognized, and they fixed the probability of the number of tags on a given n-gram exceeding the critical threshold for incrementing the counter at a constant, p. On these assumptions, the expected total tally for a test item consisting of $m$ homogeneous elements may be shown to be equal to $(2 p-1)\left(2^{\mathrm{m}}-\right.$ $\mathrm{m}-1) .^{2}$ For the original experiments of Bransford and Franks (1971), Reitman and Bower suggested that the values of $p$ for old and new test sentences might be expected to be similar to each other and greater than .5 . In this case, the functions that related the subjects' confidence ratings to the number of elements in a test sentence would also be similar and would have positive slopes, as was indeed found by Bransford and Franks. According to the tally theory, these effects should be obtained with any stimulus vocabulary that can be generated by the selection and concatenation of one or more of a set of elements. In accordance with this, Reitman and Bower demonstrated a similar pattern of results with meaningless alphanumeric character strings as the stimulus vocabulary. This suggested that the processes responsible for those results were not inherently semantic in nature. Similar experiments by Flagg (1976), Katz and Gruenewald (1974), and Small (1975) produced the same pattern of performance with strings of digits, letters, and unrelated nouns. Nevertheless, these findings do not constitute a rigorous disproof of the constructive theory as a specific account of the retention of meaningful sentences.

Reitman and Bower (1973) provided only a vague discussion of the implications of their model in terms of approximate values of the parameter $\mathrm{p}$. However, the expected relations among the recognition ratings can be derived more precisely once the actual presentation conditions have been specified (see Tyler \& Ellis, 1978). To facilitate this, one may represent a complex idea consisting of four elements by the expression ABCD. In this notation, Experiment 1 used an acquisition list consisting either of the sentences $A, C D$, and $A B C$ or of the sentences $\mathrm{D}, \mathrm{AB}$, and $\mathrm{BCD}$. All six sentences were presented during the recognition phase of the experiment. It may be noted that the tally theory assumes perfect recognition of all test sentences containing one element, and thus predicts identical distributions of responses to old and new test sentences containing only one element of a complex idea. In general, one may denote by the expression $p_{n}$ the probability that the number of tags on a given n-gram exceeds the tally threshold in the model on the basis of a single presentation of a sentence containing that $n$-gram. The expected total tallies for the specific test sentences employed in this experiment may then be derived as follows. Both old and new sentences containing two elements produce an expected total tally of $\left(2 p_{2}-1\right)$; old sentences containing three elements produce an expected total tally of $\left(6 p_{2}+2 p_{3}-4\right)$; and new sentences containing three elements produce an expected total tally of $\left(4 p_{2}-4\right){ }^{3}$

These formulas entail that old and new test sentences containing two elements should receive the same distri- bution of confidence ratings, and that new sentences containing two elements should receive more positive ratings than new sentences containing three elements. Indeed, these predictions may be shown to follow from the tally theory whatever rules are adopted for computing recognition ratings on the basis of a frequency distribution of tags across the memory representations of all possible components of the acquisition material. The account of the tally theory given by Reitman and Bower (1973) does not refer to the role of mental imagery, and whether variations in stimulus concreteness or in the experimental instructions should give rise to systematic changes in the parameters $p_{n}$ is therefore an entirely open question. However, it is quite clear that the expected relationships among the confidence ratings assigned to different test sentences should be obtained, whatever the effects of stimulus concreteness and of imagery mnemonic instructions upon overall recognition performance.

\section{Experiment 1}

\section{Method}

Subjects. Fifty-six candidates applying for admission to the Psychology Honours Degree course at Brunel University volunteered to participate in this experiment.

Materials. Six concrete ideas were taken from those used by Bransford and Franks (1971); two new abstract ideas were added to the four used by Franks and Bransford (1972). The 12 sentences expressing these ideas are shown in the Appendix. If each complex idea is denoted by the expression $A B C D$, there are 12 possible sentences expressing one or more of the four elements that can be constructed by clause embedding (James et al., 1977): A, B, $\mathrm{C}, \mathrm{D}, \mathrm{AB}, \mathrm{AC}, \mathrm{BC}, \mathrm{CD}, \mathrm{ABC}, \mathrm{ACD}, \mathrm{BCD}$, and $\mathrm{ABCD}$. Two acquisition lists were used for each idea: The first list consisted of the sentences $A, C D$, and $A B C$, and the second list consisted of the sentences $\mathrm{D}, \mathrm{AB}$, and $\mathrm{BCD}$. The recognition list for each idea consisted of all six of these sentences. It should be noted that there are three additional combinations of the four constituent elements in each complex idea, $A D, B D$, and $A B D$, that cannot be constructed by the clause embedding that is apparently demanded by Bransford and Franks's (1971) paradigm, but only by simple conjunction (e.g., "The ants were in the kitchen and the jelly was on the table").

Validation study. Two different measures of imageability and comprehensibility were obtained in order to validate the selection of stimulus material for the present investigation. Five subjects contributed to each measure, and the results were assessed by analyses of variance that treated subjects as a random factor and sentences as a fixed factor (the study was concerned with the 12 specific ideas employed in the main investigation). The subjects were tested individually, and the 12 sentences were presented in a different random order to each subject.

Imageability rating. The subjects were given questionnaires containing instructions taken from Paivio, Yuille, and Madigan (1968). Each sentence was rated on the ease or difficulty with which it aroused mental imagery along a 7-point scale. The mean imageability ratings given to the concrete and abstract sentences were 6.17 and 3.43 , respectively, and the difference between these two values was highly significant $[F(1,4)=42.96, p<.005]$.

Comprehensibility rating. The above instructions were minimally adapted to produce a similar questionnaire on the ease or difficulty with which each sentence could be understood. The mean comprehensibility ratings given to the concrete and abstract sentences were 5.53 and 5.50, respectively, and the difference between these two values was not at all significant $(F<1)$. 
Imagery latency. Following the procedure of Paivio and Begg (1971), each sentence was presented by means of a two-field tachistoscope, and the subjects pressed a response key with the preferred hand to indicate when they had made up "a mental image or picture depicting the event or scene described." An electronic timer recorded the latency of image arousal in milliseconds. The harmonic mean imagery latencies for the concrete and abstract sentences were 2.24 and $3.56 \mathrm{sec}$, respectively, and an analysis of the reciprocals of the original observations showed that the difference between these two values was highly significant $[F(1,4)=$ $31.25, \mathrm{p}<.01]$.

Comprehension latency. Whether concrete or abstract sentences differ in terms of their comprehensibility depends upon how comprehensibility is measured (Moeser, 1974; Richardson, 1980, pp. 105-106, 110-111). A relatively novel task was employed in which each subject had to encode each sentence for the purpose of answering a simple elliptical question (e.g., "Where were the ants?" or "Who proposed the goals?"). The sentence was once again presented through a tachistoscope, until the subject pressed a response key with the preferred hand to indicate his/her readiness to answer the question; the sentence was immediately replaced by a blank field, and the question was read out by the experimenter. The latency of the keypress was recorded by the electronic timer and was regarded as a measure of comprehension time. The harmonic mean comprehension latencies for the concrete and abstract sentences were 5.80 and $6.57 \mathrm{sec}$, respectively, and an analysis of the reciprocals of the original observations showed that the difference between these two values just reached statistical significance $[F(1,4)$ $=9.87, \mathrm{p}<.05]$.

Procedure. The remaining 36 subjects were tested in pairs ; they were instructed to try to remember 24 sentences in a total acquisition list, although they were not informed of the structure of the list. No specific mnemonic instructions were given to 12 of the subjects, but the others were told that "experiments have shown that a useful way of trying to remember such sentences is to try to make up a mental image of what is described by each sentence." Half were given separative imagery instructions, asking them to make up a mental image for each sentence; the other half were given interactive imagery instructions, asking them to make up complex mental images combining the events described by two or more sentences.

Within each of the three groups, two concrete ideas and two abstract ideas were selected according to a Latin square to yield "noncase" test sentences for different subgroups of four subjects; that is, no sentences expressing these ideas were included in the acquisition material at all. Two of the subjects in each subgroup learned the first acquisition list (that is, sentences $A, C D$, and $A B C$ ) of two of the remaining concrete ideas and two of the remaining abstract ideas, and the second acquisition list (that is, sentences $\mathrm{D}, \mathrm{AB}$, and $\mathrm{BCD}$ ) of the four remaining ideas; for the other two subjects in each subgroup, the material to be learned was selected in the reverse fashion. Thus, every subject learned four sentences of each of the six types, A, D, AB, CD, ABC, and BCD; and every subject learned three sentences (one containing one element, one containing two elements, and one containing three elements) expressing each of four concrete and four abstract ideas. Each total acquisition list was presented in a different random order to each pair of subjects.

The sentences, typed on plain white index cards, were presented visually at a rate of 1 every $10 \mathrm{sec}$. Immediately afterwards, each subject was instructed to carry out an irrelevant task for 5 min; the task required that the subject cancel any item that was divisible by 3 or 4 from a random array of two-digit numbers. Each pair of subjects was then presented with a full recognition set of 72 sentences ( 6 sentences for each of 12 ideas). They were asked to judge individually whether each sentence had been shown earlier and to indicate their confidence in that judgment on a numbered 5-point scale. The sentences, again typed on plain white index cards, were presented in a different random order to each subject. The responses were written on prepared response sheets, and the subjects worked through the recognition list without time pressure.

\section{Results}

Each of the 36 subjects in Experiment 1 produced a recognition response to each of the 72 test sentences; a recognition response consisted of a binary judgment ("yes" or "no") and a confidence rating. In accordance with established practice, these judgments were converted to numerical values by assigning a "plus" to an affirmative response and a "minus" to a negative response. Thus, the most confident "yes" response scored +5 , whereas the least confident "no" response scored -1 . In principle, however, the frequency of affirmative judgments and the mean confidence ratings obtained in Bransford and Franks's (1971) paradigm may show different patterns of results (Franks \& Bransford, 1974; James \& Hillinger, 1977; Singer \& Rosenberg, 1973). It was therefore considered necessary to carry out separate analyses of variance upon whether each subject had made an affirmative judgment to each test sentence and upon each subject's confidence rating on each test sentence. In fact, these analyses produced identical results and are therefore reported together; in the following account, the first statistical test reported in each pair applies to the analysis of affirmative judgments, and the second statistical test reported in each pair applies to the analysis of confidence ratings. Table 1 shows the mean percentage of affirmative judgments and the mean confidence ratings obtained with old, new, and noncase, concrete and abstract sentences expressing one, two, or three elements of a complex idea.

In each of these analyses of variance, the experimental design contained two random factors, subjects and ideas, and two fixed factors, acquisition lists and number of elements. The first random factor was nested under three fixed factors, instruction groups, noncase groups, and

Table 1

Mean Percentages of Affirmative Judgments and Mean Confidence Ratings Obtained in Experiment 1 With Test Sentences Containing One, Two, and Three Elements of Concrete and Abstract Ideas

\begin{tabular}{|c|c|c|c|c|c|c|}
\hline & \multicolumn{3}{|c|}{ Concrete } & \multicolumn{3}{|c|}{ Abstract } \\
\hline & One & Two & Three & One & Two & Three \\
\hline \multicolumn{7}{|c|}{ Mean Percentages of Affirmative Judgments } \\
\hline $\begin{array}{l}\text { Old } \\
\text { New } \\
\text { Noncase }\end{array}$ & $\begin{array}{r}75.0 \\
22.9 \\
5.6\end{array}$ & $\begin{array}{r}75.7 \\
41.7 \\
4.9\end{array}$ & $\begin{array}{l}77.8 \\
57.6 \\
12.5\end{array}$ & $\begin{array}{r}64.6 \\
21.5 \\
9.0\end{array}$ & $\begin{array}{l}67.4 \\
33.3 \\
18.8\end{array}$ & $\begin{array}{l}72.2 \\
64.6 \\
20.8\end{array}$ \\
\hline $\begin{array}{l}\text { Old - New } \\
d^{\prime} \text { (Old vs. New) }\end{array}$ & $\begin{array}{l}52.1 \\
2.33\end{array}$ & $\begin{array}{l}34.0 \\
1.05\end{array}$ & $\begin{array}{r}20.1 \\
.57\end{array}$ & $\begin{array}{l}43.1 \\
1.56\end{array}$ & $\begin{array}{r}34.0 \\
.94\end{array}$ & $\begin{array}{l}7.6 \\
.19\end{array}$ \\
\hline $\begin{array}{l}\text { New - Noncase } \\
\mathrm{d}^{\prime} \text { (New vs. } \\
\text { Noncase) }\end{array}$ & 17.4 & 36.8 & 45.1 & 12.5 & 14.6 & 43.8 \\
\hline \multicolumn{7}{|c|}{ Mean Confidence Ratings } \\
\hline $\begin{array}{l}\text { Old } \\
\text { New } \\
\text { Noncase }\end{array}$ & $\begin{array}{l}+2.43 \\
-2.17 \\
-3.83\end{array}$ & $\begin{array}{l}+2.26 \\
-.83 \\
-3.77\end{array}$ & $\begin{array}{l}+2.73 \\
+.78 \\
-3.35\end{array}$ & $\begin{array}{l}+1.29 \\
-2.35 \\
-3.51\end{array}$ & $\begin{array}{l}+1.63 \\
-1.28 \\
-2.39\end{array}$ & $\begin{array}{l}+2.17 \\
+1.36 \\
-2.56\end{array}$ \\
\hline $\begin{array}{l}\text { Old - New } \\
\text { New - Noncase }\end{array}$ & $\begin{array}{l}4.60 \\
1.66\end{array}$ & $\begin{array}{l}3.09 \\
2.94\end{array}$ & $\begin{array}{l}1.95 \\
4.13\end{array}$ & $\begin{array}{l}3.65 \\
1.15\end{array}$ & $\begin{array}{l}2.92 \\
1.10\end{array}$ & $\begin{array}{r}.81 \\
3.92\end{array}$ \\
\hline
\end{tabular}


acquisition-list groups; the second random factor was nested under two fixed factors, concreteness and noncase ideas; and the fixed factor of acquisition lists was also nested under the fixed factor of noncase ideas. The contrast comparing the old and new test sentences was interpreted as a component of the interaction between acquisition lists and acquisition-list groups; the contrast comparing the new and noncase test sentences was interpreted as a component of the interaction between noncase groups and noncase ideas. The effect of the number of elements in a test sentence was partitioned into linear and quadratic contrasts. In neither of the analyses undertaken was there any sign of an effect involving the quadratic contrast; the following account is therefore confined to a discussion of the linear effect of the number of elements in a test sentence. The effect of instruction groups was partitioned into a comparison of the two imagery groups with each other and a comparison of these two groups with the control group. Once again, in neither of the analyses undertaken was there any sign of a difference between the interactive and separative imagery groups nor any interaction involving this difference. The subjects' informal comments indicated that they simply had been unable to maintain distinct mental images under the separative imagery instructions. The following account therefore omits any further mention of this contrast and is confined to the distinction between the imagery and control groups.

The old and new test sentences were equally relevant to the general ideas or themes underlying the acquisition material, and they could be discriminated only on the basis of stored information concerning the specific sentences that had been presented for learning. The difference between the old and new test sentences in terms of the subjects' recognition performance can therefore be regarded as a measure of their ability to discriminate among sentences on the basis of specific sentence information (James \& Hillinger, 1977). This difference was significant overall [quasi $F(1,43)=42.84, p<.001$; quasi $F(1,47)=$ $86.09, p<.001]$ and interacted with the linear effect of the number of elements in a test sentence $[F(1,54)=$ 48.67, $\mathrm{p}<.001$; quasi $\mathrm{F}(1,15)=20.18, \mathrm{p}<.001]$. Table 1 shows that the retention of information about the specific acquisition sentences varied inversely with the number of elements.

The noncase test sentences could be discriminated from the old test sentences on the basis of both stored information concerning the specific acquisition material and stored information concerning the general ideas or themes underlying the acquisition material. The difference between the new and noncase test sentences in terms of the subjects' recognition performance can therefore be regarded as a measure of the subjects' ability to discriminate among sentences on the basis of general idea information. This difference was significant overall [quasi $F(1,148)=$ $68.80, p<.001 ;$ quasi $F(1,150)=77.80, p<.001]$ and also interacted with the linear effect of the number of elements in a test sentence [quasi $F(1,145)=16.70$, $\mathrm{p}<.001$; quasi $\mathrm{F}(1,167)=20.18, \mathrm{p}<.001]$. Table 1 shows that the retention of information concerning the general underlying ideas varied directly with the number of elements.

The linear effect of the number of elements in a test sentence was highly significant overall [quasi $F(1,11)=$ $15.29, \mathrm{p}<.005$; quasi $\mathrm{F}(1,13)=16.91, \mathrm{p}<.005]$. However, a posteriori tests showed that this effect was significant for the new sentences [quasi $F(1,59)=47.60$, $\mathrm{p}<.001 ;$ quasi $\mathrm{F}(1,100)=55.10, \mathrm{p}<.001]$ but not for the old sentences [quasi $F(2,59)=1.14, p>.25$; quasi $F(1,100)=2.01, p>.1]$ or for the noncase sentences [quasi $\mathrm{F}(1,48)=2.62, \mathrm{p}>.1$; quasi $\mathrm{F}(1,48)=$ $2.19, \mathrm{p}>.1]$. The differences between old and new test sentences and between new and noncase test sentences were significant for those containing one, two, and three elements ( $p<.01$ in each case). Three particular comparisons were relevant to an evaluation of the tally theory: First, old test sentences containing one element received more positive responses than new test sentences containing one element [quasi $F(1,141)=70.32$, $\mathrm{p}<.001 ;$ quasi $\mathrm{F}(1,148)=86.13, \mathrm{p}<.001]$; second, old test sentences containing two elements received more positive responses than new test sentences containing two elements [quasi $\mathrm{F}(1,141)=36.12, \mathrm{p}<.001$; quasi $\mathrm{F}(1,148)=45.87, \mathrm{p}<.001]$; third, new test sentences containing three elements received more positive responses than new test sentences containing two elements [quasi $\mathrm{F}(1,121)=19.46, \mathrm{p}<.001 ;$ quasi $\mathrm{F}(1,125)=$ $24.12, \mathrm{p}<.001]$.

The effect of the number of elements in a test sentence was not involved in any significant interactions with either the effect of stimulus concreteness or the effect of imagery instructions. Accordingly, Table 2 shows the mean

Table 2

Mean Percentages of Affirmative Judgments and Mean

Confidence Ratings Obtained in Experiment 1 With Concrete and Abstract Ideas Under Control and Imagery Instructions

\begin{tabular}{|c|c|c|c|c|}
\hline & \multicolumn{2}{|c|}{ Control } & \multicolumn{2}{|c|}{ Imagery } \\
\hline & Concrete & Abstract & Concrete & Abstract \\
\hline \multicolumn{5}{|c|}{ Mean Percentages of Affirmative Judgments } \\
\hline $\begin{array}{l}\text { Old } \\
\text { New } \\
\text { Noncase }\end{array}$ & $\begin{array}{l}73.6 \\
44.4 \\
10.4\end{array}$ & $\begin{array}{l}71.5 \\
35.4 \\
17.4\end{array}$ & $\begin{array}{r}77.4 \\
38.9 \\
6.3\end{array}$ & $\begin{array}{l}66.3 \\
42.0 \\
15.6\end{array}$ \\
\hline $\begin{array}{l}\text { Old - New } \\
d^{\prime} \text { (Old vs. New) }\end{array}$ & $\begin{array}{r}29.2 \\
.71\end{array}$ & $\begin{array}{l}36.1 \\
1.23\end{array}$ & $\begin{array}{l}38.5 \\
1.36\end{array}$ & $\begin{array}{r}24.5 \\
.58\end{array}$ \\
\hline $\begin{array}{l}\text { New - Noncase } \\
d^{\prime} \text { (New vs. Noncase) }\end{array}$ & $\begin{array}{c}34.0 \\
1.30\end{array}$ & $\begin{array}{r}18.1 \\
.62\end{array}$ & $\begin{array}{l}32.6 \\
1.51\end{array}$ & $\begin{array}{r}26.4 \\
.87\end{array}$ \\
\hline \multicolumn{5}{|c|}{ Mean Confidence Ratings } \\
\hline $\begin{array}{l}\text { Old } \\
\text { New } \\
\text { Noncase }\end{array}$ & $\begin{array}{l}+2.32 \\
-.62 \\
-3.67\end{array}$ & $\begin{array}{l}+2.03 \\
-1.27 \\
-2.97\end{array}$ & $\begin{array}{l}+2.55 \\
-.80 \\
-3.64\end{array}$ & $\begin{array}{l}+1.53 \\
-.50 \\
-2.74\end{array}$ \\
\hline $\begin{array}{l}\text { Old - New } \\
\text { Area (Old vs. New) }\end{array}$ & $\begin{array}{r}2.94 \\
.69\end{array}$ & $\begin{array}{r}3.30 \\
.71\end{array}$ & $\begin{array}{r}3.35 \\
.73\end{array}$ & $\begin{array}{r}2.04 \\
.65\end{array}$ \\
\hline $\begin{array}{l}\text { New - Noncase } \\
\text { Area (New vs. Noncase) }\end{array}$ & $\begin{array}{r}3.06 \\
.69\end{array}$ & $\begin{array}{r}1.70 \\
.60\end{array}$ & $\begin{array}{r}2.84 \\
.71\end{array}$ & $\begin{array}{r}2.24 \\
.67\end{array}$ \\
\hline
\end{tabular}


percentage of affirmative judgments and the mean confidence ratings obtained with old, new, and noncase, concrete and abstract test sentences under imagery and control instructions, without regard to the number of elements. The difference between the old and new test sentences was qualified by a three-way interaction with the effects of stimulus concreteness and imagery instructions $[F(1,18)=4.48, p<.05 ; F(1,18)=4.11, p<$ .1]. A posteriori tests showed that the two-way interaction with the effect of stimulus concreteness was significant under imagery instructions $[\mathrm{F}(1,36)=4.56, \mathrm{p}<$ $.05 ; \mathrm{F}(1,36)=6.33, \mathrm{p}<.02]$ but not under control instructions (Fs $<1$ ). Table 2 shows that information concerning the specific acquisition sentences was retained more efficiently in the case of concrete material than in the case of abstract material, but only under imagery mnemonic instructions. Similarly, there was some suggestion of a two-way interaction with the effect of imagery instructions in the case of abstract material [quasi $\mathrm{F}(1,55)=1.80, \mathrm{p}<.2 ;$ quasi $\mathrm{F}(1,55)=2.81$, $\mathrm{p}<.1]$ but not in the case of concrete material [quasi $F(2,55)=1.24, p>.25 ; F<1]$. Table 2 shows that imagery instructions tended to inhibit the retention of information concerning the specific acquisition sentences, but only with abstract material.

The difference between the new and noncase test sentences was qualified by a two-way interaction with the effect of stimulus concreteness $[\mathrm{F}(1,60)=4.16, \mathrm{p}<.05$; $\mathrm{F}(1,60)=5.64, \mathrm{p}<.025]$. Table 2 shows that concrete ideas were remembered better than abstract ideas. However, the difference between new and noncase test sentences did not interact with the effect of imagery instructions $(F s<1)$, and there was no three-way interaction with the effects of stimulus concreteness and imagery instructions $[\mathrm{F}(1,60)=1.44, \mathrm{p}>.2 ; \mathrm{F}(1,60)=1.30$, $\mathrm{p}>.25$ ]. Table 2 shows that imagery mnemonic instructions had no effect at all upon the retention of the general ideas expressed by the acquisition sentences.

A bias-free measure of recognition performance that can be obtained from the proportions of affirmative judgments is the index $\mathrm{d}^{\prime}$ of signal detection theory (see James et al., 1977). Values of d' were calculated separately for each subject for concrete and abstract sentences containing one, two, and three elements and for each of the two measures of retained information. In some cases, the hit rate was $100 \%$ or the false-alarm rate was $0 \%$, yielding an infinite value of $d^{\prime}$. To accommodate such cases (which arise inevitably in estimating a continuous variable from discrete observations), the arctangent transformation was applied to the raw data before analysis; Tables 1 and 2 show the tangents of the arithmetic means of the transformed $d^{\prime}$ scores. The values of $d^{\prime}$ obtained from the proportions of affirmative judgments given to old and new test sentences were regarded as measures of the retention of information about the specific acquisition sentences. Table 1 shows that the retention of specific sentence information was inversely related to the number of elements in a sentence. Table 2 confirms that imagery instructions inhibited the retention of specific sentence information, but only with abstract material; conversely, specific sentence information was retained more efficiently in the case of concrete material than in the case of abstract material, but only under imagery instructions. The values of $d^{\prime}$ obtained from the proportions of affirmative judgments given to new and noncase test sentences were regarded as measures of the retention of information about the general ideas or themes underlying the acquisition material. Table 1 shows that the retention of general idea information was directly related to the number of elements in a sentence. Table 2 confirms that general idea information was retained more efficiently in the case of concrete material than in the case of abstract material; however, imagery mnemonic instructions had no effect upon the retention of the general ideas or themes expressed by the acquisition sentences.

An alternative, theory-independent index of recognition performance is the area under the curve relating the hit rate and the false-alarm rate. When subjects are asked to provide confidence ratings of their judgments, several points on this curve are generated, and the relevant area can be estimated by the application of the trapezoidal rule (Pollack, Norman, \& Galanter, 1964; Richardson, 1972). This index varies between 0 and 1 and has a chance value of .5. Values of this index were calculated individually from each subject's distribution of responses across the six possible (signed) confidence ratings for concrete and abstract sentences and for each of the two measures of retained information; the arithmetic means of these scores are shown in Table 2 . The values of the area index obtained from the confidence ratings given to old and new test sentences were regarded as measures of the retention of information about the specific acquisition sentences. Table 2 confirms that specific sentence information was retained more efficiently in the case of concrete material than in the case of abstract material, but only under imagery mnemonic instructions. The values of the area index obtained from the confidence ratings given to new and noncase test sentences were regarded as measures of the retention of information about the general ideas or themes underlying the acquisition material. Table 2 shows that general idea information was retained more efficiently in the case of concrete material than in the case of abstract material, but that imagery mnemonic instructions had no effect upon the retention of general idea information.

In the validation study mentioned earlier, the concrete and abstract ideas produced a good separation on the measures of evoked mental imagery. However, there was a significant tendency for them to differ also in terms of comprehensibility, at least when this was examined by a reaction time measure. Accordingly, a multipleregression approach was employed to determine whether the significant differences identified in the previous analyses were caused by genuine differences in imageability or by the confounded variable of comprehensibility. For each of the 12 complex ideas, four independent variables were calculated: the mean rated imageability; the mean 
Table 3

Results of Stepwise Regression Analyses in Experiment 1

\begin{tabular}{lrrrrr}
\hline & \multicolumn{2}{c}{ Imagery } & & \multicolumn{2}{c}{ Comprehension } \\
\cline { 2 - 3 } \cline { 5 - 6 } & Ratings & Latencies & & Ratings & Latencies \\
\hline Control Instructions & & & & \\
$\quad$ Retention of Ideas & 13.74 & .13 & & 1.89 & .38 \\
$\quad$ Retention of Sentences & .48 & .80 & & 2.69 & .00 \\
Imagery Instructions & & & & \\
$\quad$ Retention of Ideas & 9.16 & 1.52 & & 1.34 & .98 \\
Retention of Sentences & .18 & 7.58 & .34 & .97 \\
\hline
\end{tabular}

Note $-F$ ratios shown in bold italics indicate that the independent variable accounted for a significant $(p<.05)$ amount of variation in the dependent variable and was included in the final predictive model.

rated comprehensibility; the reciprocal of the harmonic mean imagery latency; and the reciprocal of the harmonic mean comprehension latency. In addition, for each of the 12 complex ideas, two dependent variables were calculated separately for the control subjects and for those given imagery mnemonic instructions: the difference between the mean confidence rating given to the old sentences and the mean confidence rating given to the new sentences, as a measure of the retention of specific sentence information; and the difference between the mean confidence rating given to the new sentences and the mean confidence rating given to the noncase sentences, as a measure of the retention of general idea information. Stepwise regression analyses were carried out to determine the extent to which the four independent variables could predict each of the four dependent variables. Table 3 shows the $F$ ratios relating to each independent variable for the final predictive models; a significant entry indicates that the variable was in the final predictive model for the appropriate dependent variable. It is evident that the retention of the original ideas was predicted by rated imageability under both imagery and control instructions, but that the retention of the specific sentences expressing those ideas was predicted by imagery latency only under imagery mnemonic instructions. (In each case, the regression coefficient had the anticipated sign.) Otherwise, none of the independent variables was a significant predictor of any of the dependent variables. Thus, Table 3 confirms the effects that were identified in the previous analyses but incorporates the distinction between rating and latency measures of imageability. Similar results were obtained when the dependent variables were based upon differences in the proportions of affirmative responses, upon the corresponding values of $d^{\prime}$, and upon the area index obtained from the distributions of confidence ratings.

\section{Discussion}

The pattern of results obtained in this experiment was fairly clear, regardless of the measure of recognition performance employed. This in itself has certain interesting implications. First, the concordance between the conventional difference scores and the bias-free measures of sensitivity implies that the principal effects of interest reflected genuine variations in recognition accuracy rather than mere fluctuations in response bias. Second, the concordance between the binary (yes/no) recognition judgments and the confidence ratings is consistent with the idea that the major variations in performance were associated with changes in the subjects' tendencies to make affirmative or negative judgments, rather than in the distribution of their confidence ratings within these two judgmental categories (cf. Franks \& Bransford, 1974; James et al., 1977; Singer \& Rosenberg, 1973). Finally, the concordance between the $d^{\prime}$ measure of signal detection theory and the theory-independent area index indicates that the same general conclusions may be drawn from this study whether or not one cares to make any parametric assumptions about the mechanisms that might have generated the subjects' recognition judgments.

In the recognition-memory paradigm that they devised, Bransford and Franks (1971) found that subjects tended to confuse old and new test sentences expressing the same complex ideas, and they concluded that the subjects had integrated the propositional content of the acquisition sentences to construct holistic semantic ideas. The present experiment has extended these findings to a situation in which semantic integration was not complete, and thus ceiling effects were avoided. Although the old and new test sentences received overlapping distributions of responses, the difference between these distributions was both quite apparent and statistically significant on all four measures of recognition accuracy. This incidentally enables one to reject a suggestion put forward by Lawson (1977) that subjects in Bransford and Franks's paradigm merely respond on the basis of a sentence's truth value. Under the appropriate presentation conditions, subjects are able to demonstrate some retention of the specific acquisition sentences (cf. James et al., 1977). Moreover, under standard learning instructions, the present experiment found roughly similar, nontrivial levels of retention of specific sentence information with concrete and abstract material. Equivalently, the degree of semantic integration was largely independent of stimulus concreteness, even when the presentation conditions ensured that only a moderate or partial level of integration was attained overall. This is inconsistent with the imagery theory of Paivio (1971a, 1971b), which predicted that concrete material would be better integrated in the form of mental images, whereas abstract material would be stored in a specific verbatim form. However, these results are entirely consistent with the constructive theory of Bransford and Franks (1971), which predicted no effect of stimulus concreteness on the grounds that the synthesis of information into holistic representations employed abstract semantic processes that did not depend upon the concretization of that information in the form of mental imagery.

Another procedural manipulation for investigating the role of mental imagery is the use of imagery mnemonic instructions. On the one hand, Experiment 1 failed to find a significant effect of such instructions upon the integration of concrete ideas. This result is also entirely consistent with the constructive theory, since it regards the use 
of mental imagery as being essentially irrelevant to the processes of semantic integration. However, the imagery theory should predict that such instructions would facilitate the integration of concrete material in the form of composite mental images, which would lead to poorer retention of information about the specific sentences that had been presented for learning. On the other hand, imagery mnemonic instructions did tend to disrupt the retention of abstract acquisition sentences; conversely, the apparent level of semantic integration with abstract material was enhanced under imagery mnemonic instructions. It is difficult for the imagery theory to explain this result, since it would predict no facilitation of the integrative processes with sentences expressing abstract ideas. However, the constructive theory can handle this finding, since it regards the creation of mental images as an irrelevant cognitive task that might well disrupt the subjects' retention of information concerning the specific acquisition sentences. In other words, the interaction between the effects of stimulus concreteness and imagery instructions upon sentence retention was precisely the opposite of that which had been predicted on the imagery theory, but precisely in accordance with that which might be expected on the constructive theory. Under imagery mnemonic instructions, there was a significant positive effect of stimulus concreteness upon the retention of specific sentence information, which appeared to be associated with concomitant variations in the latency of evoked mental imagery. This supports the constructive theory even more directly, since it suggests that the retention of specific sentence information was a function of the amount of processing time available to the subjects after the irrelevant task of creating mental images had been completed

In Experiment 1, the subjects tended overall to make more positive judgments about test sentences that contained more elements. However, it is perhaps more interesting that the difference between old and new test sentences varied inversely with the number of elements, as in previous investigations (Bransford \& Franks, 1971; Franks \& Bransford, 1972; Richardson, 1983). Such a relationship appeared even when a bias-free measure of recognition accuracy was employed to evaluate the retention of the specific acquisition sentences. This finding is inconsistent with the contention of James et al. (1977) that variations in the discrimination of old and new test sentences with the number of elements are purely the result of fluctuations in response bias. It confirms the suggestion of Bransford and Franks (1972) that information concerning the specific acquisition sentences is more readily retained in the case of those with fewer elements. This might result from the greater discriminability of such sentences (James \& Hillinger, 1977) or, as suggested earlier in this paper, from limitations in the capacity of immediate memory. There was also an unexpected direct relationship between the number of elements in a test sentence and the difference between "new" sentences expressing the original ideas and "noncase" sentences expressing entirely different ideas. This difference was interpreted as a measure of the retention of the original ideas as general themes underlying the acquisition material, but the reason for the interaction is not clear. Previous studies have rarely used noncase sentences of the sort employed here and have typically not considered the effect of the number of elements contained in such sentences.

Experiment 1 also demonstrated a consistent and substantial effect of stimulus concreteness upon the retention of the general ideas or themes underlying the acquisition material. This effect appeared to be associated with concomitant variations in the rated ease of image arousal. In itself, this is entirely consistent with the imagery theory of Paivio (1971a, 1971b). However, the dissociation between the effects of imagery latency and rated imageability upon sentence retention and idea retention is rather problematic, because the imagery theory attributes the retention and integration of complex ideas to a common mechanism. Moreover, the superior retention of concrete ideas can be handled readily by constructive or propositional theories of long-term memory, if it can be assumed that encoded representations that incorporate spatial or perceptual predicates are more distinctive or are more richly structured (Richardson, 1980, pp. 87, 90, 107). This interpretation is supported by the fact that the retention of general idea information in Experiment 1 was not affected in any way by instructing the subjects to use mental imagery as a mnemonic strategy.

The tally theory of Reitman and Bower (1973) fared no better than the imagery theory as an account of the pattern of performance to be obtained in Experiment 1. The particular version of the tally theory that was described by Reitman and Bower specifically predicted identical distributions of responses to old and new test sentences containing only one element of a complex idea. This prediction was clearly negated by the results of Experiment 1 , which found a substantial difference between old and new test sentences containing one element, both in terms of the proportion of affirmative responses and in terms of the mean confidence ratings. However, this prediction does not follow from other versions of the tally theory. Two further predictions were that old and new test sentences containing two elements should receive the same distribution of confidence ratings and that new sentences containing two elements should receive more positive ratings than new sentences containing three elements. These predictions follow from the tally theory for the presentation conditions employed in Experiment 1, whatever rules are adopted for computing recognition ratings on the basis of a frequency distribution of tags across the memory representations of all possible components of the acquisition materials. Nevertheless, both of these predictions were refuted soundly by the findings of Experiment 1 .

Although the results of Experiment 1 tend to support the constructive theory of semantic integration, there are four important respects in which they fail to provide an adequate test of that model. First, the materials employed in Bransford and Franks's (1971) paradigm exhibit not 
only semantic relatedness, but also semantic similarity. James and Hillinger (1977) pointed out that the pattern of results that is normally attributed to the operation of semantic integration might therefore be the result of semantic confusion and interference. Second, any unequivocal predictions that can be derived from the constructive theory in connection with Bransford and Franks's (1971) original paradigm are essentially those of null effects. Third, in any case, the constructive theory must be applied to other experimental situations if it is to be regarded as having general explanatory capacity. Finally, the results presented thus far count against all theories that describe recognition judgments of complex stimuli in terms of computations based on a frequency distribution of occurrence tags across all possible components of those stimuli (e.g., Hayes-Roth \& Hayes-Roth, 1977; Neumann, 1974; cf. Hintzman \& Ludlam, 1980; Medin \& Schaffer, 1978). However, they do not rule out all classes of theories that are based upon the decomposition of stimulus information into simple propositional elements. To handle these criticisms, Experiments 2 and 3 employed a cued-recall paradigm in order to contrast the model proposed by Bransford and Franks (1971) with an alternative componential analysis of mnemonic representation.

\section{THE FRAGMENTATION THEORY}

Jones (1976) developed this theory to explain the pattern of performance obtained in cued recall when the constituents of each complex stimulus are independent of one another. Jones proposed that the memory trace representing a particular stimulus consisted of one or more "fragments" of that stimulus, each containing a nonoverlapping subset of the elements of that stimulus. At the time of recall, the provision of one of these elements as a cue would reinstate the whole fragment in an all-or-none fashion. This model was found to provide an accurate account of performance with sequences of pictures or descriptions of common objects and with lists of unrelated complex sentences (Jones, 1976, 1978; Jones \& Payne, 1982). Nevertheless, Jones's analysis contains two separate assumptions that need to be carefully distinguished. First, what one may call "the componential analysis" holds that the memory trace derived from a set of complex stimuli consists of one or more components of those stimuli, each containing a subset of the elements of those stimuli. Second, what Jones (1976) called the "fragmentation hypothesis" makes the stronger claim that each of these components is a fragment, in that it contains a nonoverlapping subset of the elements of one particular stimulus.

The sentences employed by Jones (1978) and by Jones and Payne (1982) satisfied the requirements of orthogonal cued recall, in that all of the sentences in a given experiment had the same structure and the items inserted into that structure were chosen in an independent manner. If, on the contrary, there are preexisting specific relations among the constituent elements of a stimulus, then the fragmentation process may need to be augmented by qualitatively different mechanisms involving the generation and recognition of candidate responses (Jones, 1979, 1980). The materials used in Experiment 1 did not strictly satisfy the requirements of orthogonal cued recall, since the same concept often occurred in more than one element of a complex idea ("The ants were in the kitchen," "The ants ate the jelly") and therefore the constituents of a particular stimulus were not formally independent of one another. Nevertheless, the likelihood of correct responses' being produced in a cued-recall task with such materials purely as a result of guessing is negligible. Thus, the constituent elements of a particular stimulus are likely to be functionally independent of one another, and cued recall should be based solely upon the retrieval of encoded components. Accordingly, Experiment 2 considered the applicability of the componential analysis to such materials.

\section{Experiment 2}

\section{Method}

Subjects. Thirty-six candidates applying for admission to the Psychology Honours Degree course at Brunel University volunteered to participate.

Materials. The acquisition materials were sentences expressing the six concrete and six abstract ideas that were employed in Experiment 1 (that is, sentences of the form $A B C D$ ). The recall cues for each of these ideas were sentences expressing six possible fragments of the original acquisition sentences: $\mathrm{A}, \mathrm{B}, \mathrm{C}, \mathrm{D}, \mathrm{ABC}$, and BCD.

Procedure. A Latin square was employed to assign the six recall cues to the six concrete and six abstract ideas for different subjects, so that each subject received every possible type of recall cue twice but was tested only once on each idea. This Latin square was replicated six times across the 36 subjects. The subjects were tested in three groups of 12 , and each group received the 12 acquisition sentences in a different random order; they were presented on slides at a rate of 1 every $10 \mathrm{sec}$, and the subjects were instructed simply to "try to remember them." They then carried out the previously described number-canceling task for $5 \mathrm{~min}$. The recall cues were presented on successive pages of a response booklet, randomly ordered for each individual subject. The subjects were asked to "write down on each page anything else you can remember about the event or scene concerned," and they were allowed 1 min for each item.

\section{Results and Discussion}

An independent judge was employed to score the responses obtained in Experiments 2 and 3. She was asked to determine which elements of each complex idea were correctly represented, at least in terms of their gist, in each subject's response to the appropriate recall cue. Table 4 shows the relative frequency of occurrence of each of the 36 possible patterns of recall cues and correctly recalled elements across the 36 subjects.

The statistical analysis of these data followed the procedures of Jones (1976, 1978) exactly. In particular, contingency tables were submitted to a likelihood-ratio analysis using Kullback's (1959, p. 85) minimum discrimination information statistic, $2 \hat{\mathrm{I}}$, which is asymptotically distributed as chi-square. Not surprisingly, the 
Table 4

Observed and Expected Percentages of Occurrence of Each Possible Combination of Recall Cue and Correctly Recalled Elements in Experiment 2

\begin{tabular}{|c|c|c|c|c|c|c|c|}
\hline \multirow{2}{*}{$\begin{array}{l}\text { Cue } \\
\text { Type }\end{array}$} & \multirow{2}{*}{$\begin{array}{l}\text { Correctly } \\
\text { Recalled }\end{array}$} & \multicolumn{2}{|c|}{ Concrete } & \multicolumn{2}{|c|}{ Abstract } & \multicolumn{2}{|c|}{ Overall } \\
\hline & & Data & Theory & Data & Theory & Data & Theory \\
\hline A & $\mathrm{BCD}$ & 30.56 & 8 & .78 & 4 & 9.17 & 23.21 \\
\hline A & $\mathrm{BC}$ & 11.11 & 5.38 & 5.56 & & 8.33 & 4.54 \\
\hline A & $\mathrm{BD}$ & .00 & .86 & .00 & .96 & .00 & .91 \\
\hline A & $\mathrm{CD}$ & 16.67 & 11.67 & 2.78 & 1.84 & 9.72 & 7.00 \\
\hline A & B & 13.89 & 11.89 & 11.11 & & 12.50 & 10.11 \\
\hline A & C & .00 & 3.23 & 8.33 & 9.37 & 4.17 & 6.18 \\
\hline A & $\mathrm{D}$ & .00 & .00 & .00 & 1.49 & .00 & .67 \\
\hline A & zero & 27.78 & 39.81 & 44.44 & 54.69 & 36.11 & 47.38 \\
\hline B & & 36.11 & 27.18 & 2.22 & 19.24 & 29.17 & 23.21 \\
\hline B & & .00 & 5.38 & 2.78 & 3.96 & 1.39 & 4.54 \\
\hline B & & .00 & .86 & .00 & .96 & .00 & .91 \\
\hline B & $C D$ & 33.33 & 24.39 & 19.44 & 13.81 & 26.39 & 19.05 \\
\hline B & $\mathbf{A}$ & 5.56 & 11. & 2.78 & & .17 & 10.11 \\
\hline B & C & 5.56 & 7.70 & 5.56 & 6. & .56 & 6.78 \\
\hline B & D & .00 & .00 & 2.78 & 3. & 1.39 & 1.79 \\
\hline B & ze & 19.44 & 22.62 & 44.44 & 43.52 & 31.94 & 33.61 \\
\hline C & & 19.44 & 27. & 8.33 & & 13.89 & 23.21 \\
\hline C & & 2.78 & & 2.78 & & .78 & 4.54 \\
\hline C & $\mathrm{A}$ & 13.89 & 11. & .00 & 1.84 & .94 & 7.00 \\
\hline C & BD & 25.00 & 24.39 & 16.67 & 13.81 & 20.83 & 19.05 \\
\hline C & 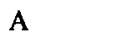 & 5.56 & 3.23 & 8.33 & 9. & 6.94 & 6.18 \\
\hline C & B & 8.33 & 7.70 & 8.33 & 6.3 & 8.33 & 6.78 \\
\hline C & D & 13.89 & 8.70 & 8.33 & 4. & 11.11 & 6.73 \\
\hline C & zero & 11.11 & 11.77 & 47.22 & 40.76 & 29.17 & 26.51 \\
\hline D & $\mathrm{ABC}$ & 27.78 & 27.18 & 19.44 & 19.24 & 23.61 & 23.21 \\
\hline D & $\mathrm{AF}$ & 2.78 & .8 & 2.78 & .96 & 2.78 & .91 \\
\hline D & AC & 5.56 & 11.67 & 2.78 & 1.84 & 5.56 & 7.00 \\
\hline D & BC & 25.00 & 24.39 & 11.11 & 13.81 & 18.06 & 19.05 \\
\hline D & A & .00 & .00 & 2.78 & 1.49 & 1.39 & .67 \\
\hline D & B & .00 & .00 & 5.56 & 3.68 & 2.78 & 1.79 \\
\hline D & $\mathrm{C}$ & 8.33 & 8.70 & 2.78 & 4.64 & 5.56 & 6.73 \\
\hline $\mathrm{D}$ & zer & 27.78 & 27.22 & 52.78 & 54.34 & 40.28 & 40.64 \\
\hline $\mathrm{ABC}$ & $\mathrm{D}$ & 61.11 & 72.80 & 38.89 & & 50.00 & 59.36 \\
\hline $\mathrm{ABC}$ & zer & 38.89 & & 61.11 & & 50.00 & 40.64 \\
\hline BC & A & 58.33 & 60.21 & 50.00 & & 54.17 & 52.62 \\
\hline 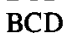 & zer & 41.67 & 39.81 & 50.00 & 54.69 & 45.83 & 47.3 \\
\hline
\end{tabular}

obtained recall performance shown in Table 4 differed significantly between the concrete and abstract ideas [2Î( $(30)$ $=53.86, \mathrm{p}<.005]$, generally indicating poorer performance in the case of abstract material.

Table 5 shows the 15 different types of inferred component that are relevant to this experiment. There are three "twin components" that express the possibility of two independent, nonoverlapping components' being derived from the same acquisition sentence. The null component includes cases in which the residual component contained only one element of the original acquisition sentence, which would have been ineffective in cued recall. The expected composition of the data in terms of these 15 different component types can be specified fairly easily; for instance, the correct recall of elements $B$ and $C$ but not element $D$ when the subject was cued with element $A$ implies a component of the form ABC. However, not all of the data classes are uniquely specifiable in this manner, and thus many of the components are not identifiable; for instance, the correct recall of element B but not elements $C$ and $D$ when the subject was cued with element $\mathrm{A}$ implies either a component of the form $\mathrm{AB}$ or a twin component of the form (AB, CD). Following Jones (1976), rough initial estimates of the relative frequencies of occurrence of the 15 possible components were obtained by simple averaging and algebraic manipulations. These estimates were then adjusted by a computer program using an iterative penalty function technique (Lootsma, 1972), so as to minimize the statistic 21̂ for the fit of theory to data. This process yielded the theoretical frequency distributions shown in Table 4 and the maximumlikelihood estimates shown in Table 5.

For each of the sets of observed and expected data shown in Table 4, there were 30 independent classes of data and 14 free parameters, leaving 16 degrees of freedom for testing the fit of theory to data. In the case of the overall frequency distribution obtained by combining the data from concrete and abstract ideas, the information statistic comparing the observed and expected frequencies was significant $[2 \hat{\mathrm{I}}(16)=30.31, \mathrm{p}<.02]$. However, the information statistic was not significant for

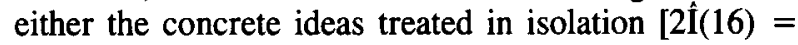
$22.23, \mathrm{p}>.1$ ] or the abstract ideas treated in isolation $[2 \hat{\mathbf{I}}(16)=17.14, \mathrm{p}>.3]$, and the net overall statistic was not significant $[2 \mathrm{I}(32)=22.23+17.14=39.36$, $\mathrm{p}>.1]$.

Statistical comparison of the componential parameters obtained with concrete and abstract ideas was undertaken with the procedure described by Jones (1978). First, an arcsine transformation was applied to the values shown in Table 5; this resolves the measurement and scaling problems associated with proportional data and emphasizes differences occurring at either end of the measurement scale. Second, for each of the 15 possible components, the squared difference between the transformed values for concrete and abstract ideas was calculated. Third, an onion-peeling procedure was used to determine which of these squared differences were significantly larger than the average of the remainder. The comparisons for Component Types 15, 4, and 10 were statisti-

Table 5

Maximum-Likelihood Estimates of the Percentages of Occurrence of Each Type of Component in Experiment 2

\begin{tabular}{rlrrr}
\hline Type & Component & Concrete & Abstract & Overall \\
\hline 1 & ABCD & 27.18 & 19.24 & 23.21 \\
2 & ABC & 5.38 & 3.96 & 4.54 \\
3 & ABD & .86 & .96 & .91 \\
4 & ACD & 11.67 & 1.84 & 7.00 \\
5 & BCD & 24.39 & 13.81 & 19.05 \\
6 & AB & 9.78 & 8.45 & 10.11 \\
7 & AC & 3.23 & 9.37 & 6.18 \\
8 & AD & .00 & 1.49 & .67 \\
9 & BC & 7.70 & 6.38 & 6.78 \\
10 & BD & .00 & 3.68 & 1.79 \\
11 & CD & 6.59 & 4.64 & 6.73 \\
12 & AB, CD & 2.11 & .00 & .00 \\
13 & AC, BD & .00 & .00 & .00 \\
14 & AD, BC & .00 & .00 & .00 \\
15 & Null & 1.13 & 26.18 & 13.03 \\
\hline
\end{tabular}


cally significant $[F(1,13)=15.46, p<.005 ; F(1,12)$ $=4.79, \mathrm{p}<.05$; and $\mathrm{F}(1,11)=5.24, \mathrm{p}<.05$, respectively], but that for the next highest difference (Type 12) was not $[F(1,10)=3.64, p>.05]$. Once again, it was not surprising that the significant differences between the componential parameters obtained with concrete and abstract ideas tended to reflect somewhat poorer recall in the case of abstract material.

It should be noted that the maximum-likelihood estimates shown in Table 5 for the "twin components" approached zero, indicating that the complex stimuli tended to be retained as coherent wholes. It is also interesting that the maximum-likelihood estimates also approached zero for components that reflected complex sentences that cannot be constructed by clause embedding, but only by simple conjunction (AD, $\mathrm{BD}$, and $\mathrm{ABD})$. It is in fact well known that conjunctival association does not by itself produce an integrated form of representation in memory (Begg \& Young, 1977; Bower, 1972). Thus, it is to be expected that propositional elements that are linked only by conjunctions would not constitute a stable or effective form of associative representation.

It has of course already been shown that a componential analysis provides an accurate representation of cued recall in the case of structured linguistic material (Jones, 1978; Jones \& Payne, 1982). However, Experiment 2 has extended the generality of this finding to include performance with complex sentences that have an articulated propositional structure, although the results also suggest that the concreteness of the stimulus material has to be taken into account. These results are not in themselves at odds with the constructive theory of Bransford and Franks $(1971,1972)$. However, the theory proposed by Jones (1976) includes the strong assertion that each component in memory constitutes a fragment of a single stimulus item. This "fragmentation hypothesis" is formally inconsistent with Bransford and Franks's (1971) contention that information from different stimuli may be integrated into holistic semantic representations. Experiment 3 therefore contrasted the constructive and fragmentation theories by applying the componential analysis to the recall of complex ideas expressed by sets of related acquisition sentences.

\section{Experiment 3}

\section{Method}

Subjects. Forty-eight candidates applying for admission to the Psychology Honours Degree course at Brunel University volunteered to participate.

Materials. The acquisition materials were sentences expressing components $\mathrm{A}, \mathrm{CD}$, and $\mathrm{ABC}$ of each of the 12 ideas employed in Experiment 1. The recall cues were the same as those employed in Experiment 2.

Procedure. The procedure was identical to that of Experiment 2, except that each group of 12 subjects was presented with the 36 acquisition sentences in a different random order, with the constraint that no two sentences relating to the same idea be presented in succession. The Latin square assigning the six recall cues to the six concrete and six abstract ideas was replicated eight times across the 48 subjects.

\section{Results and Discussion}

As mentioned earlier, an independent judge was employed to score the subjects' responses. Table 6 shows the relative frequency of occurrence of each of the 36 possible patterns of recall cues and correctly recalled elements across the 48 subjects. Once again, the concrete and abstract ideas produced significantly different patterns of recall performance $[2 \hat{\mathrm{I}}(30)=69.14, \mathrm{p}<.001]$, indicating poorer performance in the case of the abstract material.

Table 7 shows the 18 different types of inferred component that are relevant to Experiment 2. There are six single components and four "twin components" that might arise by a process of fragmentation: That is, each of these components contains a subset of the elements in one particular stimulus. Three of the "twin components" are also "overlapping components" in the sense that a particular element (C) occurs in both components. There are also six single components and two "twin components" that could arise only by a process of integration, in that one component contains information from more

Table 6

Observed and Expected Percentages of Occurrence of Each Possible Combination of Recall Cue and Correctly Recalled Elements in Experiment 3

\begin{tabular}{|c|c|c|c|c|c|c|c|}
\hline \multirow{2}{*}{$\begin{array}{l}\text { Cue } \\
\text { Type }\end{array}$} & \multirow{2}{*}{$\begin{array}{l}\text { Correctly } \\
\text { Recalled }\end{array}$} & \multicolumn{2}{|c|}{ Concrete } & \multicolumn{2}{|c|}{ Abstract } & \multicolumn{2}{|c|}{ Overall } \\
\hline & & Data & Theory & Data & Theory & Data & Theory \\
\hline $\bar{A}$ & $\mathrm{BCD}$ & 14.58 & 16.46 & 8.33 & 7.95 & 11.46 & 12.22 \\
\hline A & $\mathrm{BC}$ & 14.58 & 16.39 & 8.33 & 13.09 & 11.46 & 14.54 \\
\hline A & BD & .00 & .00 & 2.08 & .73 & 1.04 & .34 \\
\hline A & $C D$ & 25.00 & 22.18 & 6.25 & 8.94 & 15.63 & 15.66 \\
\hline A & B & 6.25 & 6.16 & 14.58 & 13.84 & 10.42 & 10.08 \\
\hline A & $\mathrm{C}$ & 6.25 & 6.12 & 12.50 & 11.96 & 9.38 & 8.89 \\
\hline A & D & .00 & 1.62 & .00 & & .00 & 1.40 \\
\hline A & zero & 33.33 & 31.08 & 47.92 & 42.42 & 40.63 & 36.88 \\
\hline B & $\mathrm{ACD}$ & 0.83 & 16.46 & 6.25 & 7.95 & 13.54 & 12.22 \\
\hline B & $\mathrm{AC}$ & 0.83 & 16.39 & 20.83 & 13.09 & 20.83 & 14.54 \\
\hline B & $A D$ & .00 & .00 & .00 & .73 & .00 & .34 \\
\hline B & $C D$ & 8.33 & 8.84 & 2.08 & 4.85 & 5.21 & 5.78 \\
\hline B & A & 8.33 & 6.16 & 16.67 & 13.84 & 12.50 & 10.08 \\
\hline B & $\mathrm{C}$ & 6.25 & 7.76 & 4.17 & 4.19 & 5.21 & 5.77 \\
\hline B & D & .00 & .00 & .00 & .00 & .00 & .00 \\
\hline B & zero & 35.42 & 44.40 & 50.00 & 55.35 & 42.71 & 51.28 \\
\hline C & $A B D$ & 14.58 & 16.46 & 4.17 & 7.95 & 9.38 & 12.22 \\
\hline 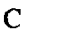 & $\mathrm{AB}$ & .67 & 16.39 & 14.58 & 13.09 & 15.63 & 14.54 \\
\hline $\mathrm{C}$ & $\mathrm{AD}$ & .17 & 22.18 & 8.33 & 8.94 & 18.75 & 15.66 \\
\hline C & BD & 6.25 & 8.84 & 2.08 & 4.85 & 4.17 & 6.06 \\
\hline$C$ & A & 8.33 & 6.12 & 16.67 & 11.96 & 12.50 & 8.89 \\
\hline C & B & 6.25 & 7.76 & 4.17 & 4.19 & 5.21 & 5.49 \\
\hline 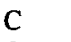 & D & 14.58 & 17.14 & 6.25 & 8.71 & 10.42 & 13.67 \\
\hline C & zero & 17 & 5.12 & 43.75 & 40.31 & 23.96 & 23.48 \\
\hline D & $\mathrm{ABC}$ & 18.75 & 16.46 & 12.50 & 7.95 & 15.63 & 12.22 \\
\hline D & $\mathrm{AB}$ & .00 & .00 & .00 & .73 & .00 & .34 \\
\hline D & $\mathrm{AC}$ & 20.83 & 22.18 & 12.50 & 8.94 & 16.67 & 15.66 \\
\hline D & $\mathrm{BC}$ & 4.17 & 4.32 & 8.33 & 4.85 & 6.25 & 5.91 \\
\hline D & A & 4.17 & 1.62 & 2.08 & 1.07 & 3.13 & 1.40 \\
\hline D & B & .00 & .00 & .00 & .00 & .00 & .00 \\
\hline D & C & 20.83 & 21.66 & 8.33 & 8.71 & 14.58 & 13.82 \\
\hline D & zero & 31.25 & 33.77 & 56.25 & 67.75 & 43.75 & 50.66 \\
\hline $\mathrm{ABC}$ & D & 64.58 & 66.24 & 37.50 & 32.25 & 51.04 & 49.35 \\
\hline $\mathrm{ABC}$ & zero & 35.42 & 33.77 & 62.50 & 67.75 & 48.96 & 50.66 \\
\hline $\mathrm{BCD}$ & $\mathrm{A}$ & 58.33 & 68.93 & & 57.58 & 55.21 & 63.13 \\
\hline $\mathrm{BCD}$ & zero & 41.67 & 31.08 & 47.92 & 42.42 & 44.79 & 36.88 \\
\hline
\end{tabular}


Table 7

Maximum-Likelihood Estimates of the Percentages of Occurrence of Each Type of Component and of the Value of Each Determinate Mediating Parameter in Experiment 3

\begin{tabular}{|c|c|c|c|c|}
\hline Type & Component & Concrete & Abstract & Overall \\
\hline \multicolumn{5}{|c|}{ Fragmentation Components } \\
\hline 1 & $\mathrm{ABC}, \mathrm{CD}$ & .00 & .00 & .00 \\
\hline 2 & $\mathrm{AB}, \mathrm{CD}$ & 6.16 & .00 & 2.18 \\
\hline 3 & $\mathrm{AC}, \mathrm{CD}$ & .00 & .00 & .00 \\
\hline 4 & $\mathrm{BC}, \mathrm{CD}$ & 4.94 & .00 & .77 \\
\hline 5 & $\mathrm{ABC}$ & 16.39 & 13.09 & 14.54 \\
\hline 6 & $\mathbf{A B}$ & .00 & 13.84 & 7.90 \\
\hline 7 & $\mathrm{AC}$ & 6.12 & 11.96 & 8.89 \\
\hline 8 & $\mathrm{BC}$ & 6.14 & 4.19 & 5.49 \\
\hline 9 & $\mathrm{CD}$ & 10.98 & 8.71 & 11.49 \\
\hline 10 & Null & 5.12 & 24.67 & 13.84 \\
\hline \multicolumn{5}{|c|}{ Integration Components } \\
\hline 11 & $\mathrm{ABCD}$ & 16.46 & 7.95 & 12.22 \\
\hline 12 & $\mathrm{ABD}$ & .00 & .73 & .34 \\
\hline 13 & $\mathrm{ACD}$ & 22.18 & 8.94 & 15.66 \\
\hline 14 & $\mathrm{BCD}$ & 3.90 & 4.85 & 5.29 \\
\hline 15 & $\mathrm{AD}$ & .00 & 1.07 & 1.40 \\
\hline 16 & $\mathrm{BD}$ & .00 & .00 & .00 \\
\hline 17 & $\mathrm{AC}, \mathrm{BD}$ & .00 & .00 & .00 \\
\hline 18 & $\mathrm{AD}, \mathrm{BC}$ & 1.62 & .00 & .00 \\
\hline \multicolumn{5}{|c|}{ Mediating Parameters } \\
\hline $\begin{array}{l}\mathrm{ABC} \rightarrow \mathrm{CD} \\
\mathrm{AC} \rightarrow \mathrm{CD}\end{array}$ & & & & \\
\hline $\mathrm{BC} \rightarrow \mathrm{CD}$ & & 1.0000 & & .6352 \\
\hline $\mathrm{CD} \rightarrow \mathrm{ABC}$ & & & & \\
\hline $\mathrm{CD} \rightarrow \mathrm{AC}$ & & & & \\
\hline $\mathrm{CD} \rightarrow \mathrm{BC}$ & & .0852 & & .8004 \\
\hline
\end{tabular}

than one particular stimulus. Finally, there are two additional parameters associated with each "overlapping component" to define the probability that one fragment in the component acts as a mediator for the other; thus, the first of these parameters defines the probability that the fragment ABC (as reinstated by either Stimulus A or Stimulus $B$ ) in turn reinstates the fragment $C D$ and thus permits the recall of the whole idea ABCD. As in Experiment 2, the fit of theory to data was optimized by numerical methods, following the procedures of Jones $(1976,1978)$ exactly. This yielded the theoretical frequency distributions shown in Table 6 and the maximumlikelihood estimates shown in Table 7.

The mediating parameters were indeterminate when the corresponding componential parameters were estimated to be zero. [For instance, when the relative frequency of occurrence of the component $(\mathrm{ABC}, \mathrm{CD})$ was estimated to be zero, there was no way of estimating the probability that $A B C$ would reinstate $C D$ or vice versa.] Thus, for each of the sets of observed and expected data shown in Table 6, there were 30 independent classes of data, 17 free componential parameters, and between 0 and 6 free determinate mediating parameters, leaving between 7 and 13 degrees of freedom for testing the fit of theory to data. In the case of the overall frequency distribution obtained by combining the data from concrete and abstract ideas, the information statistic comparing the observed and ex- pected frequencies was significant $[2 \hat{\mathrm{I}}(11)=20.60, \mathrm{p}<$ $.05]$. However, the information statistic was not significant for either the concrete ideas treated in isolation $[2 \hat{I}(11)=10.82, p>.3]$ or the abstract ideas treated in isolation $[2 \hat{\mathrm{I}}(13)=17.12, \mathrm{p}>.1]$, and the net overall statistic was not significant $[2 \hat{\mathbf{I}}(24)=10.82+17.12=$ 27.94, $\mathrm{p}>.25$ ].

Once again, statistical comparison of the componential parameters obtained with concrete and abstract ideas was undertaken using the procedure described by Jones (1978). The comparisons for Component Types 6, 10, 2, and 4 were statistically significant $[\mathrm{F}(1,16)=7.71, \mathrm{p}<.02$; $\mathrm{F}(1,15)=5.89, \mathrm{p}<.05 ; \mathrm{F}(1,14)=5.73, \mathrm{p}<.05 ;$ and $\mathrm{F}(1,13)=6.32, \mathrm{p}<.05$, respectively]. However, the comparison for the next highest difference (Type 1) was not significant $[F(1,12)=4.10, p>.05]$. As in Experiment 2, the maximum-likelihood estimates for the "twin components" approached zero, as did those for components reflecting complex sentences that cannot be constructed by clause embedding, but only by simple conjunction ( $\mathrm{AD}, \mathrm{BD}$, and $\mathrm{ABD}$ ).

This experiment supported the conclusion of Experiment 2 , that the componential analysis developed by Jones (1976) provides an accurate account of cued recall in the case of structured linguistic material, at least when the concreteness of that material is taken into account. However, the parameters identified by Jones's "fragmentation hypothesis" have to be supplemented by parameters that represent components that could arise only by the integration of information from different stimulus items. In other words, the process of fragmentation postulated by Jones (1976) has to be augmented by the process of semantic integration described by Bransford and Franks (1971, 1972). The significant differences between the componential parameters obtained with concrete and abstract ideas tend to reflect somewhat poorer performance in the case of abstract material, but they arise specifically in the values of the fragmentation parameters, not in the values of the integration parameters. This is consistent with the conclusions of Experiment 1, that stimulus concreteness affects the retention of complex ideas but has no effect upon the integration of those ideas.

\section{GENERAL CONCLUSIONS}

This study has provided two sorts of empirical validation for the notion that propositional elements may be integrated into higher order semantic representations. First, in a test of recognition memory, subjects tended to confuse the original acquisition sentences with new test sentences expressing the same complex ideas. In Experiment 1 , this confusion was not total, and some discrimination between old and new test sentences was observed, indicating that it is possible to manipulate the process of semantic integration experimentally. Second, in a test of cued recall, subjects tended to demonstrate patterns of performance that reflected the integration of propositional elements from distinct stimulus presenta- 
tions. Although there was obviously some forgetting of propositional information, Experiment 3 showed the occurrence of recall patterns that could not be produced solely by the loss of information from individual stimulus items. It thus provided a specific response to the demand of James and Hillinger (1977) for a new paradigm in which to investigate semantic integration.

The contrary viewpoint is that the retention of individual phrases or sentences is to be described purely in terms of the decomposition of specific information concerning distinct stimulus items. As a potential rival to the constructive theory of Bransford and Franks (1971), this was first suggested by Reitman and Bower (1973). Their tally theory, which held that subjects retained information concerning the occurrence of all possible combinations of the elements in each stimulus presentation, was contradicted by the confidence-rating data of Experiment 1 . Since this theory is concerned mainly with the decision rules employed in recognition memory, it could be extended to encompass recall paradigms only by making additional, ad hoc assumptions (but cf. Hayes-Roth \& Hayes-Roth, 1977). In contrast, Bransford and Franks's (1971) constructive theory could be subsumed directly within the componential analysis of cued recall that was employed in Experiments 2 and 3. A rather different account of memory developed by Jones $(1976,1978)$ attempted to describe the encoded memory trace as one particular combination of the elements in each stimulus presentation. This was contradicted by the results of Experiment 3, which demonstrated the occurrence of patterns of performance that could not arise as the result solely of the process of fragmentation described by Jones. Thus, although the present investigation has not ruled out all possible alternatives to the constructive approach, it has conclusively rejected the two sets of theoretical proposals that constitute clearly articulated alternatives to that approach.

Each of the experiments in this paper found a clear effect of stimulus concreteness upon the retention of complex sentences and upon the loss of elements from those sentences. This effect might be ascribed to the use of mental imagery as a form of mnemonic representation, but in this case it is surprising that in Experiment 1 instructions to use mental imagery had no effect at all upon the retention of complex ideas. An alternative explanation that is more in accord with recent research on the propositional structure of long-term memory is that the occurrence of perceptual or spatial predicates enhances the retention of encoded descriptions. Moreover, this investigation has found no evidence at all that mental imagery enhances the integration of complex ideas. Experiment 1 demonstrated equivalent levels of integration in the case of concrete and abstract ideas and indicated that requiring the subjects to create mental images merely imposed an irrelevant task that reduced their total processing capacity. Experiment 3 showed that the establishment of integrative representations was equally likely to occur in the case of concrete and abstract material. On the one hand, these findings are extremely problematic for the im- agery theory proposed by Paivio (1971a, 1971b, 1977, 1978). On the other hand, the results of the present investigation lend considerable support to the constructive theory suggested by Bransford and Franks (1971) and elaborated by Bransford et al. (1972) which holds that propositional integration is based upon the construction of abstract semantic descriptions, not upon the concretization of information in the form of mental images.

\section{REFERENCES}

BegG, I., \& Paivio, A. (1969). Concreteness and imagery in sentence learning. Journal of Verbal Learning and Verbal Behavior, 8, 821-827.

BeGG, I., \& YounG, B. J. (1977). An organizational analysis of the form class effect. Journal of Experimental Child Psychology, 23, 503-519.

BowER, G. H. (1972). Mental imagery in associative learning. In L. W. Gregg (Ed.), Cognition in learning and memory. New York: Wiley.

Bransford, J. D., Barclay, J. R., Franks, J. J. (1972). Sentence memory: A constructive versus interpretative approach. Cognitive Psychology, 3, 193-209.

Bransford, J. D., \& Franks, J. J. (1971). The abstraction of linguistic ideas. Cognitive Psychology, 2, 331-350.

Bransford, J. D., \& Franks, J. J. (1972). The abstraction of linguistic ideas: A review. Cognition, 1, 211-249.

Cofer, C. N. (1973). Constructive processes in memory. American Scientist, 61, 537-543.

FLAGG, P. W. (1976). Semantic integration in sentence memory? Journal of Verbal Learning and Verbal Behavior, 15, 491-504.

Franks, J. J., \& BranSFord, J. D. (1972). The acquisition of abstract ideas. Joumal of Verbal Learning and Verbal Behavior, 11, 311-315.

Franks, J. J., Bransford, J. D. (1974). A brief note on linguistic integration. Journal of Verbal Learning and Verbal Behavior, 13, 217-219

Griggs, R. A. (1974). The recall of linguistic ideas. Journal of Experimental Psychology, 103, 807-809.

HAYES-RoTh, B., \& HAYES-RoTh, F. (1977). Concept learning and the recognition and classification of exemplars. Joumal of Verbal Leaming and Verbal Behavior, 16, 321-338.

Hintzman, D. L., \& Ludlam, G. (1980). Differential forgetting of prototypes and old instances: Simulation by an exemplar-based classification model. Memory \& Cognition, 8, 378-382.

JAMES, C. T., \& Hillinger, M. L. (1977). The role of confusion in the semantic integration paradigm. Journal of Verbal Learning and Verbal Behavior, 16, 711-721.

James, C. T., Hillinger, M. L., \& MurPhy, B. J. (1977). The effects of complexity on confidence ratings in linguistic integration. Memory \& Cognition, 5, 355-361

JARVELLA, R. J. (1970). Effects of syntax on running memory span for connected discourse. Psychonomic Science, 19, 235-236.

JARVELLA, R. J., \& HERMAN, S. J. (1972). Clause stucture of sentences and speech processing. Perception \& Psychophysics, 11, 381-384.

JONES, G. V. (1976). A fragmentation hypothesis of memory: Cued recall of pictures and of sequential position. Joumal of Experimental Psychology: General, 105, 277-293.

JONES, G. V. (1978). Tests of a structural theory of the memory trace. British Journal of Psychology, 69, 351-367.

JONES, G. V. (1979). Analyzing memory by cuing: Intrinsic and extrinsic knowledge. In N. S. Sutherland (Ed.), Tutorial essays in psychology: A guide to recent advances (Vol. 2). Hillsdale, NJ: Erlbaum.

JONES, G. V. (1980). Interaction of intrinsic and extrinsic knowledge in sentence recall. In R. S. Nickerson (Ed.), Attention and performance VIII. Hillsdale, NJ: Erlbaum.

JONES, G. V., \& PAYNE, M. S. (1982). Recall and the flexibility of linguistic processing. In A. Flammer \& W. Kintsch (Eds.), Discourse processing. Amsterdam: North-Holland.

KATZ, S. (1973). Role of instructions in abstraction of linguistic ideas. Journal of Experimental Psychology, 98, 79-84. 
KATZ, S., AtKeson, B., \& LeE, J. (1974). The Bransford-Franks linear effect: Integration or artifact? Memory \& Cognition, 2, 709-713.

Katz, S., \& Gruenewald, P. (1974). The abstraction of linguistic ideas in "meaningless" sentences. Memory \& Cognition, 2, 737-741.

KULlBaCK, S. (1959). Information theory and statistics. New York: Wiley.

LAWSON, R. (1977). Representation of individual sentences and holistic ideas. Journal of Experimental Psychology: Human Learning and Memory, 3, 1-9.

Lootsma, F. A. (1972). A survey of methods for solving constrained minimization problems via unconstrained minimization. In F. A. Lootsma (Ed.), Numerical methods for non-linear optimization. London: Academic Press.

Marscharck, M., \& Paivio, A. (1977). Integrative processing of concrete and abstract sentences. Journal of Verbal Learning and Verbal Behavior, 16, 217-231.

Medin, D. L., \& Schaffer, M. M. (1978). Context theory of classification learning. Psychological Review, 85, 207-238.

MoESER, S. D. (1974). Memory for meaning and wording in concrete and abstract sentences. Journal of Verbal Learning and Verbal Behavior, 13, 682-697.

MOESER, S. D. (1975). The integration of verbal ideas. Canadian Journal of Psychology, 29, 106-123.

NeISSER, U. (1972). Changing conceptions of imagery. In P. W. Sheehan (Ed.), The function and nature of imagery. New York: Academic Press.

NeumanN, P. G. (1974). An attribute frequency model for the abstraction of prototypes. Memory \& Cognition, 2, 241-248.

PaIvio, A. (1971a). Imagery and language. In S. J. Segal (Ed.), Imagery: Current cognitive approaches. New York: Academic Press.

PaIvio, A. (1971b). Imagery and verbal processes. New York: Holt, Rinehart \& Winston.

PaIvio, A. (1972). A theoretical analysis of the role of imagery in learning and memory. In P. W. Sheehan (Ed.), The function and nature of imagery. New York: Academic Press.

PaIVIO, A. (1977). Images, propositions, and knowledge. In J. M. Nicholas (Ed.), Images, perception, and knowledge. Dordrecht: Reidel.

PaIvio, A. (1978). Dual coding: Theoretical issues and empirical evidence. In J. M. Scandura \& C. J. Brainerd (Eds.), Structural/process models of complex human behavior. Alphen: Sijthoff \& Noordoff.

PaIvIo, A., \& BEGG, I. (1971). Imagery and comprehension latencies as a function of sentence concreteness and structure. Perception \& Psychophysics, 10, 408-412.

Paivio, A., Yuille, J. C., \& Madigan, S. A. (1968). Concreteness, imagery, and meaningfulness values for 925 nouns. Journal of $E x-$ perimental Psychology Monographs, 76(1, Pt. 2).

PEZDEK, K. (1978). Recognition memory for related pictures. Memory \& Cognition, 6, 64-69.

Pollack, I., Norman, D. A., \& Galanter, E. (1964). An efficient non-parametric analysis of recognition memory. Psychonomic Science, $1,327-328$.

Reitman, J. S., \& Bower, G. H. (1973). Storage and later recognition of exemplars of concepts. Cognitive Psychology, 4, 194-206.

RICHARDSON, J. T. E. (1972). Nonparametric indexes of sensitivity and response bias. Psychological Bulletin, 78, 429-432.

RichaRDSON, J. T. E. (1980). Mental imagery and human memory. London: Macmillan.

RICHARDSON, J. T. E. (1983). Further evidence on the abstraction of linguistic ideas. Bulletin of the Psychonomic Society, 21, 439-442.

SACHS, J. S. (1967). Recognition memory for syntactic and semantic aspects of connected discourse. Perception \& Psychophysics, 2, 437-442.

SINGER, M. (1973). A replication of Bransford and Franks' (1971) "The abstraction of linguistic ideas." Bulletin of the Psychonomic Society, $1,416-418$

Singer, M., \& Rosenberg, S. T. (1973). The role of grammatical relations in the abstraction of linguistic ideas. Journal of Verbal Learning and Verbal Behavior, 12, 273-284.

SMALL, D. W. (1975). The abstraction of arbitrary categories. Memory \& Cognition, 3, 581-585.
TYLER, S. W., \& ElLIS, H. C. (1978). A test of alternative models of sentence recognition. Bulletin of the Psychonomic Society, 12, 375-377.

\section{NOTES}

1. Marscharck and Paivio (1977) apparently accepted the inadequacy of the imagery theory for handling the integrative processing of sentential material. They found that concrete material produced superior performance on both verbatim and substance recall, but their argument focused upon a comparison of these two measures. Unfortunately, their results were subject to an obvious floor effect, in that the use of the more lenient substance scoring criterion produced only minimal increases over the stricter verbatim criterion. Indeed, their subjects appear to have responded largely on the basis of the verbatim expression of the original sentences, and their experiment is thus uninformative of the role of more abstract, integrative processing. Moreover, Paivio $(1977,1978)$ has reaffirmed his support for an imagery theory of semantic integration.

2. The probability of adding a tally for each n-gram is $p$, whereas the probability of subtracting a tally for each n-gram is $(1-p)$. The expected increase in the counter as a result of inspecting each $n$-gram is therefore $(+1)(p)+(-1)(1-p)=2 p-1$. The total number of unordered combinations of elements of any size that may be chosen from a pool of size $\mathrm{m}$ is $2^{\mathrm{m}}$, but this includes the single case representing the choice of no elements at all and $m$ different cases representing a choice of one individual element. Thus, the number of n-grams contributing to the accumulating tally is $2^{\mathrm{m}}-\mathrm{m}-1$. Multiplying this by the expected increase as a result of inspecting each n-gram yields the formula given for the expected total tally. As Richardson (1983) pointed out, this expression is different from the formula given by Reitman and Bower (1973). In discussing the sort of stimulus material used by Bransford and Franks (1971), Reitman and Bower suggested that the procedure for combining the elements of a complex idea was that of clause embedding. They concluded that in this case there would be $\left(2^{\mathrm{m}}-1\right)$ possible components or $n$-grams of a complex idea containing $m$ elements. This overlooks the fact that not all of these components can be constructed by clause embedding, a point that is explained later in the present paper. Nevertheless, in specifying their tally model, Reitman and Bower apparently restricted the relevant combinatory procedure to the simple concatenation of ordered, adjacent elements of arbitrary strings: for instance, $A B, B C$, and $B C D$, but not $A C, B D$, or $A C D$. (This is nowhere explicitly stated or justified by the authors, however.) In this case, there are only $m(m-1) / 2$ possible components or n-grams of a string containing $m$ elements, and this does yield the formulas given by Reitman and Bower. However, Tyler and Ellis (1978) pointed out an implication of Reitman and Bower's model, that the function relating the confidence ratings to the number of elements in a test sentence would have a negative slope for sentences composed of sets of nonadjacent elements if the acquisition sentences had all been composed of sets of adjacent elements. Tyler and Ellis found a clear positive slope, which is inconsistent with the particular tally model described by Reitman and Bower, although not with a variant that permits all possible combinations of elements. Accordingly, it is the latter version that is described in the present paper.

3. Both old and new test sentences containing two elements should produce a tally +1 from the corresponding digram with a probability of $p_{2}$ and a tally of -1 from that digram with a probability of $\left(1-p_{2}\right)$; this yields an expected total tally of $\left(2 p_{2}-1\right)$. Old sentences containing three elements should produce a tally of +1 from each of their three possible digrams with a probability of $p_{2}$, a tally of -1 from each of those digrams with a probability of $\left(1-p_{2}\right)$, a tally of +1 from the corresponding trigram with a probability of $\mathrm{p}_{3}$, and a tally of -1 from that trigram with a probability of $\left(1-p_{3}\right)$; this yields an expected total tally of $\left(6 p_{2}+2 p_{3}-4\right)$. Finally, new test sentences containing three elements should produce a tally of +1 from two of their three possible digrams with a probability of $p_{2}$, a tally of -1 from each of those two digrams with a probability of $\left(1-p_{2}\right)$, a tally of -1 from the third digram, and a tally of -1 from the corresponding trigram; this yields an expected total tally of $\left(4 p_{2}-4\right)$. 


\section{APPENDIX}

Stimulus Materials

The 12 complex sentences employed in this investigation are listed below. For each sentence, the following indexes are shown: the mean rated imageability; the mean rated comprehensibility; the harmonic mean imagery latency; and the harmonic mean comprehension latency. The two former measures were obtained from the use of a 7-point rating scale, and the two latter measures are in seconds.

$\mathrm{C} 1$. The ants in the kitchen ate the sweet jelly which was on the table. $(5.8,5.0,2.12,5.62)$

C2. The old car pulling the trailer climbed the steep hill. $(6.4,5.0,2.02,4.84)$

C3. The tall tree in the front yard shaded the man who was smoking his pipe. $(6.4,5.6,2.64,5.77)$

C4. The warm breeze blowing from the sea stirred the heavy evening air. $(6.2,6.0,2.31,6.48)$

C5. The rock which rolled down the mountain crushed the tiny hut at the edge of the woods. $(6.8,6.0,2.70,7.44)$

C6. The girl who lives next door broke the large window on the porch. $(5.4,5.6,1.87,5.31)$

A1. The arrogant attitude expressed in the speech led to immediate criticism. $(3.4,5.2,4.02,5.66)$

A2. The intense desire to be successful can determine all personal actions. $(4.4,6.0,3.16,7.55)$

A3. The emotional appeal for support elicited unselfish sympathy. $(3.2,4.4,4.46,6.92)$

A4. The unrealistic goals proposed by the leader resulted in frequent disillusionment. $(2.8,6.0,4.26,7.42)$

A5. The brilliant mathematician with a sense of humour proved the difficult theorem. $(3.6,5.6,3.31,6.68)$

A6. The official inquiry set up by the government ignored the central issue. $(3.2,5.8,2.78,5.72)$

(Manuscript received January 30, 1984;

revision accepted for publication September 10, 1984.) 